\title{
The precautionary principle under fire
}

\section{Rupert Read and Tim O'Riordan}

The precautionary principle carries great significance for 'sustainability science'. It provides a powerful framework for improving the quality, decency and reliability of decisions over technology, science, ecological and human health, and improved regulation of riskburdened human affairs. It asks us to pause and to review before leaping headlong into innovations that might prove disastrous. Such a call does not sit well with a 'deregulatory' (i.e. environmentally-non-protecting) policy setting, nor with the expectation by corporates of maintaining profit in an economic climate where competition is yelping and recession is barking at the door.

Because of this, the precautionary principle is now under fire. Looking across the world, we find a paradox. The precautionary principle is entrenched in government and legal systems in various places, but most strikingly in the European Union (EU). It has a presence in the patterns and processes of environmental management right across the $\mathrm{EU}$. It is therefore especially alarming that the precautionary principle is under considerable threat in the EU. Specifically, it may be at risk in trade treaties currently being negotiated (https://www.uea.ac.uk/about/media-room/eu-referendum/ttip-and-eu ); it is being challenged by the rival so-called Innovation Principle (http://esharp.eu/debates/innovation/the-innovationprinciple ); and it may be at severe risk in the U.K. as part of the Brexit process (see e.g. http://www.foodmanufacture.co.uk/Food-Safety/Food-safety-precautionary-principle-mustcontinue-post-Brexit).

This issue of Environment both reaffirms the need for and asserts the changing nature of the precautionary principle. It seeks to update the precautionary principle to meet the emerging scientific and technological challenges of the 21st century, and in particular the sometimes seemingly inevitable processes of potential human-triggered harm that now hang over us.

\section{The precautionary principle in context}

Precaution emerged as a central tenet of European environmental policy in the mid 1970 s (Boehmer-Christiansen, 1994; Jordan, 2001, Gee 2013). This period has been heralded as the period of expansionism in environmental policy and management. Precaution made sense when introducing a fundamental way of stopping realistically irreversible environmental problems from arising at all. During this period the precautionary principle 
gained strength partly because it was accompanied by other innovative regulatory approaches to environmental policy-making. These included the principle of prevention (better than cure); stimulation of the best available technology for increasing the efficiency of resource use and of preventing waste; safeguarding zones of environmental nurture in the face of ignorance or uncertainty by (in part) setting a cap on overall alteration; sharing the burden of responsibilities according to contribution and ability to pay; assuring proportionality of regulatory action when setting gains against losses; sharing regulatory responsibilities between government and commerce via responsible intervention by accredited non-governmental organizations; providing conditions for the survival of future generations and ecosystems; and making the polluter pay. The most ambitious claim of precaution was to place the burden of proof of not causing avoidable danger onto any decision-maker proposing to introduce or regulate new products, technologies or infrastructure developments. Its genius lay in making it clear that absence of certainty, or there being insufficient evidence-based analysis, were not impediments to innovation, so long as there was no reasonable likelihood of serious harm. Crucially, precaution enjoins innovatory paths not only against imposing hazard, but also to stop exposing us to any potential risks of such harm.

The precautionary principle reached its global apogee as Principle 15 of the Rio Declaration on Environment and Development agreed by all UN nations in 1992:

In order to protect the environment, the precautionary approach shall be widely applied by States according to their capabilities. Where there are threats of serious or irreversible damage, lack of full scientific certainty shall not be used as a reason for postponing cost-effective measures to prevent environmental degradation. ${ }^{1}$

In essence, the precautionary principle imposes a duty of planetary care on the human will. It seeks to deepen, to widen, and to lengthen all manner of so-called impact assessments. Above all, it provides a basis for public discussion and deliberation over what kind of society and moral accountability we collectively should choose to adopt. Such decisions have to be collective. ${ }^{2}$ It is conceptually impossible for a society to leave it up to individuals or corporations to choose what technology to select when there may be all manner of consequences for others. ${ }^{3}$ Leaving such decisions to individuals or corporations is simply a defective way of expressing that collective will (or lack of will). Precaution therefore comes

\footnotetext{
${ }^{1}$ We note that the term "serious or irreversible" is probably slightly unfortunate: because it may imply that irreversible but trivial harms need to be guarded against. Whereas presumably they don't. So a formulation like "serious, especially if irreversible" would probably be a happier formulation. ...Then again, the "serious or irreversible" formulation could be precautionarily defended, on the grounds that it can be doubted whether any truly irreversible change is truly trivial.

2 This point is present powerfully in the work of Hannah Arendt; see particularly The human condition. See also Christopher Groves' work in recent years, and Anne Chapman's article in this issue.

${ }^{3}$ Anne Chapman's article in the present issue of Environment develops this point. See also her http://www.greenhousethinktank.org/uploads/4/8/3/2/48324387/greens and science inside 2.pdf.
} 
with responsible and genuinely democratic governance, not always a popular concept in the harassed economies and politics of today.

Precaution is more recognized in the European regulatory culture than is the case for the US. We take this further in our discussion of the Innovation Principle, much favored in the US, but under intense scrutiny in the EU. The dividing line here is the role of innovation and accountability to risk taking which tend to be given greater weight in US regulation and court procedures, along with a more flamboyant approach to learning through experimentation. Most of the papers in this edition of Environment explore the cost, actual and potential, of such flamboyance.

We argue here that since the Rio Declaration, the precautionary principle has been steadily downgraded. For this issue we commissioned a number of illuminating companion papers to explain why this is the case, and to suggest what can be done about it.

The themes of these papers are:

evidentiary proof (Anne Chapman)

liability and onus of responsibility and compensation (Iancu Daramus)

participatory involvement in assessment procedures for novel technologies (Ricarda Steinbrecher and Helena Paul)

the changing international dimension (Andrew Boswell)

The main message of this package is that the sustainability process in general is being progressively weakened at a time when we can least afford such weakening, that various forms of good environmental governance are being undermined in terms of effective citizen participation, and that in particular the legitimate and legislative foundations of the precautionary principle are being dismantled and removed.

The decline of this principle is a synecdoche for the challenges facing 'sustainability science'. If future pathways of both sustainability science and a resurgent precautionary principle can be forged together then there is a brighter future for the entire precautionary and riskmanagement process and, by extension, for humanity and its posterity.

The precautionary principle was introduced to create a basis for thoughtful and considered evaluation of policy, technology, scientific discovery, and innovative ways of providing foresight. This enjoyed transatlantic recognition. It also tied in with emerging safeguards to public health and to avoidance of vulnerability to natural hazard via warnings, evacuation and zoning procedures. It was conceived at a time when environmental disruption, particularly from toxic chemicals, was becoming a matter of widespread public concern. The UN Conference on the Human Environment, held in Stockholm in 1972, opened up the issue of cross-border legal responsibilities for curtailing damaging pollution at source and 
strengthened the emerging national and international environmental regulatory regimes, particularly on the European continent.

As these arrangements were being put in place, it became clear that reliable information and prognoses were limited or imperfect. It was not possible to await confirmation of harm and the source of harm whilst environmental damage from neighboring countries was palpably occurring. Thus there was an urgent need for a mechanism which did not merely follow the path of normal scientific methodology. Scientists are typically concerned above all to avoid false positives, or 'false alarms'. This bias explains why many scientists are relatively cautious in their claims and public pronouncements. If one is willing to take the risk of obeying (what may turn out to be) 'false positives', then one might be shown to having been more pessimistic than the circumstances warrant.

Yet the risk of operating on the basis of false negatives is arguably far worse. Here we have in mind the avoidance or ignorance of a (potentially) serious unanticipated outcome. One's shining scientific reputation is of little moment, compared to possible complicity in the undermining of possible serious/irreversible avoidable harm. If one sticks too tightly to the normal scientific habit of awaiting the evidence and avoiding false alarms, one may be complicit in a situation where something genuinely and massively alarming and dreadful occurs - without one having warned against it.

Before the introduction of the precautionary principle, the international order did not have a way of facilitating an appropriate methodology for scientific deliberations of this nature. Thus it did not have political currency for careful examination and assessment of what are sometimes coyly called the 'distributional aspects' of techno-scientific developments - the downsides of possible and plausible longer term outcomes from any potentially-dangerous initiating actions. This was also true of within-nation environmental damage notably linked to large infrastructure schemes such as pipelines and power stations. Hence precaution was established for ensuring a more reflective and weighted approach to preparing for uncertain and potentially destabilising global and local futures for people and nature. Precaution means that one no longer has to wait for proof; one can take the risk of engendering false positives, in order to be confident of being able to avert false negatives. In other words: in order not to give a false sense of reassurance that could then 'legitimate' actions that turned out to be harmful. Precaution seeks to ensure that such harms do not knowingly occur; it does so by reversing the normal burden of proof.

The precautionary principle is also notable for its consideration of social and ecological resilience and wellbeing across all forthcoming generations. It places emphasis on political and moral mechanisms for widening the basis for assessing outcomes over generations to come and for the health of the planet as a whole. There is no other legal or regulatory framework for ensuring such a critical feature of human empathy and care. Precaution is a 
way of implementing a deep future-care, of the kind called for by so many, including notably Hans Jonas ${ }^{4}$ and the present Pope. ${ }^{5}$

For Aristotle, courage is the moderate position between fearfulness and rashness or recklessness. ${ }^{6}$ Recklessness is the absence of precaution - the absence of prudence. Recklessness is the stance that we are seeking to critique in this special issue. It characterizes much of our fundamental lack of organized care towards our ecosystems and the welfare of future generations. We also argue that at times a version of recklessness in the context of technology and of certain approaches to modeling can masquerade under the banner of science itself. If we are correct in this interpretation, then courage is called for in defending foresight and care for the future.

\section{The power of precaution in its initial formulation}

The precautionary principle is an heir to the German Vorsorgeprinzip (BoehmerChristiansen, 1994: 33-43). Though often interpreted as 'foresight', Vorsorge applies to responsible and equitable appraisal of future action. 'Fore-care' is a useful literal translation.

Lying behind and manifested in the evolution of this interpretation were both a sense of provable responsibility for public, civic and private actions, and a sharing of accountability between the state, the change-agent and the electorate. In this sense, precaution connects with more recent trends in the deliberative approaches to uncertainty and forecasting, as well as to the question of methods of calculating (for instance) toxicity and biodiversity damage.

Today, there is a greater willingness to accept regulatory voluntarism as an expression of self-styled corporate social responsibility. This is despite continuing skepticism of such voluntarism amongst justifiably wary public interest groups. The early rise of precaution relied more on formal rules of engagement and consensus amongst business, unions and civil society brokered by the state. Nowadays the more formal strictures of precaution are being undermined. The deliberate involvement of business, especially in self-regulation, and the moving away from pure regulatory adversarialism may lead to a weakening in the actual force of precautionary reasoning and law with regard to those who do not engage in decent/sustainable practice. It is particularly relevant that the requirement to show no

\footnotetext{
${ }^{4}$ The imperative of responsibility: the search for an ethics for a technological age (Chicago: U. Chicago Press, 1979).

${ }^{5}$ See his remarkable 'Laudato Si' encyclical: http://w2.vatican.va/content/francesco/en/encyclicals/documents/papafrancesco 20150524 enciclica-laudato-si.html .

${ }^{6}$ See Nicomachean Ethics 1107a30-1107b4. P.118 in the Broadie and Rowe edition.
} 
harm and to offer compensation to those who suffer from residual harm has softened both in legal and regulatory terms. The accompanying articles on liability and evidentiary proof attest to this shift of emphasis.

In the UK the emergence of the prestigious and multidisciplinary Royal Commission on Environmental Pollution in 1970 (Owens 2015) coincided with a deepening ethical and even theological interpretation of precaution. In its path-breaking reports on radioactive waste, setting environmental standards, restricting marine pollution, avoiding possible toxic effects of pesticides and incineration, removing lead from gasoline, and exploring the scope of genetically modified organisms, the Commission imaginatively explored the widening of the precautionary principle.

The thoughtful analyses by Susan Owens $(2015,76-102)$ of the evolution in thinking and conceptualization by the Royal Commission provides a wonderful insight into the changing context of interpreting the precautionary principle. She begins in the early years of the Commission's work, in the 1970s, where there was a robust debate over the assimilative capacities of air and water and the need to control pollution at the emitting source rather than through natural cleansing processes. Both the changing characteristics of pollutants promoting more inorganic and synthetic components as well as the need to stimulate the technologies of removal brought the Commission more towards the continental approach of restricting discharges at source. This shift revealed the changes in both environmental and the composition of effluents. But it also opened up the Commission to a more moral view on avoidable harm as well as a greater degree of meaningful participation in the environmental management process.

This process accompanied the rise of 'citizen science' and the need to recognize that public values underpinned all environmental standard setting and not just the views of the expert and the scientific elite. As a consequence, the Commission broadened its perspective on precaution to take into account the ethical aspects of acting and regulating under conditions of imperfect knowledge. It also reinforced its views on the need to be mindful of the distributional aspects of environmental harm on employees, on the general public, and on particular cultures (for example the introduction of lead based products in the cosmetic industry with particular exposure to women from the Indian sub-continent).

What we see here in this fascinating period of the 1980s and 90s was a subtle shift in the discourse over precaution. Where there was a failure to take anticipatory action, especially where the scientific evidence was inconclusive but sufficiently robust to show likely harm (as in the case of bio-accumulative chemicals), it became evident to regulators that there was a strong ethical and legally pragmatic case for urging restriction. In this important sense this experience heralded the subtle shift towards the highly contentious but precautionarily- 
commonsensical stance of shifting the burden of proof onto the promoter of novel technologies and substances.

What was also occurring during this period was a changing notion of the role of the environmental scientist. The remarkable story of the removal of lead in gasoline in the early 1980s (RCEP 1983) was a classic example of challenging the received wisdom of much decorated health scientists. They became regarded as too close to the automotive and oil industries. In addition, the extremely spirited campaigns of the anti-lead activists (Wilson 1983), as well as more general feeling that playing with the possible decline of intelligence in children (particularly those living in poor areas with high levels of car-borne air pollution) was plain wrong. Here we see the vital connection between scientific assessments and a deep sense of ethical responsibility.

This case may well in fact be one of many examples where an innovation enjoined by precaution (i.e. removing lead from fuel) has led to systemic spin-off benefits. There is some evidence that the decrease in crime over recent decades is due to the removal of lead from fuel. ${ }^{7}$ If this is true the benefits of removing lead will have been far greater than was thought at the time.

Recent work by researchers at Lancaster University found active carbonaceous particles from exhaust emissions in brains and concluded that this might be causal in developing Alzheimer's. ${ }^{8}$ A recent study in Canada suggested that risk of Alzheimer's was greater for people living near busy roads. ${ }^{9}$ Of course, these studies are not decisive. The point is that they provide further precautionary reasons for bringing down the level of atmospheric pollution coming from motor vehicles, and for various associated policy responses (restricting and even eliminating the diesel engine, reducing the need to travel, adjusting idling to the point of automatic shut-off, and locating schools further from main roads).

The Royal Commission's investigations are highlighted here as they reveal more generally the changing context of precaution over the past 25 years. In terms of sustainability science, the lifeblood of this Magazine, the rise of knowledge brokering as more of a participatory conversation, the emergence of the scientist as a learner as much as a practitioner, and the more recent emphasis on empathy as a key ingredient in sustainability decision-making are taking place as part of the evolution of the precautionary concept. We observe the emergence of deliberative procedures in relation to such areas as geo-engineering, genetic modification, nano technology, and the medical ethics surrounding such delicate matters as

\footnotetext{
${ }^{7}$ http://www.bbc.co.uk/news/magazine-27067615

${ }^{8}$ https://www.newscientist.com/article/2104654-air-pollution-is-sending-tiny-magnetic-particles-into-yourbrain/

${ }^{9} \mathrm{http}: / /$ www.aljazeera.com/news/2017/01/scientists-link-dementia-risk-living-busy-roads170105103825153.html
} 
stem cell research and triple donors of sperm and eggs through a process covered in an accompanying article by Paul and Steinbrecher as 'Gene Drives'.

In all of this we see a fascinating relationship between precaution holding on, but doing so in a setting of much more widespread social and scientific change. Part of our message here is that the synergy of the two sets of progressions, namely precaution clinging on rather tenuously, and sustainability science emerging a little more strongly, provides a healthy introduction to but not a reliable basis for any successful progress for sustainability science.

In all of this flurry of mid-1980s legislation, the precautionary principle was invoked to ensure that the integrity of ecosystems-functioning was protected, that primary biodiversity was enhanced, and that human health and wellbeing were given attention, especially where minority rights of class, ethnicity, gender and culture and the welfare of future generations were concerned. In its early formulation(s), precaution championed the interests of the two unseen and unheard components of the planet: future generations, especially of the poor and politically disadvantaged, and ecological assemblages and interconnections, which combine to retain life and habitability on this arguably unique planet.

We turn to contemporary environmental governance and politics to see just how well these early achievements have fared and why they are faltering.

\section{Mid-life crisis}

The original ideals for precaution, especially shifting the burden of proof onto the promoter, together with strong and social justice driven regulatory arrangements, have been weakening, arguably at the very time that they need strengthening. This is in part a direct result of deregulatory pressure. In the case of toxic pesticides, for example, the evidence is instructive. A group of pesticides known as neonicotinoids, closely associated with damage to insect pollinators, especially bees, should have been banned on the basis of precaution (Environmental Audit Committee 2014). Instead, after extensive lobbying by the farming and agro-chemical industries, the European Commission announced initially a three-year temporary ban to explore the outcomes of the trial removal. It is impossible for ecological science to prove one way or another that such a 'fallow period' would show the effects on bee populations which are under attack from many sources. A new study (Woodcock et al 2017) conducted in three countries, found that neonicotinoids were associated with declines in the reproduction of both honey bees and wild bees. Yet a companion study (Stockstad et al 2017), carried out only in Germany, claimed that some bee populations seemed to be unaffected. Such apparently contradictory findings evoke our comments on scientists' sometimes-excessive wariness of false positives just as the EU is poised completely to ban this widely used and in agricultural circles very popular pesticide. 
The precautionary response of the EU here seems to us well warranted: the key point being that the complexity and time-lags of ecology imply that, when the stakes are high (as they are with bees), rash profit-seeking is irrational. Moreover, the uncertainties are raised further because of the intersection with global over-heat (i.e. temperature shifts), and consequent rising levels of pathogens, which are or are likely to be affecting the habitats and genetics of bees. Pollinating plants are shifting in composition and location, while changes in vegetation are confusing bees' foraging practices.

The kinds of discussion initiated by the Royal Commission and by the UK Environmental Audit Committee shows that inconclusive evidence can, unfortunately, act as a restraint on the application of precaution, especially where that evidence is unusual or untested, as is the case with climate change relevant effects. ${ }^{10}$ So it is easier for politically well-situated lobbies, who are extremely well financed and politically connected, to create doubt in the minds of the regulator or legislator. And in a world where the agro-chemical companies are seeking to respond to public concerns at least notionally, it is harder for the precautionfavoring campaigners to get political leverage. In this important sense the changing political and regulatory dynamics associated with the production and use of the very substances which used to trigger precautionary actions, are nowadays working against the basic principles of the concept. This seems to us a matter of grave regret.

\section{A 'case study': genetically modified organisms}

On the key battle front of genetically modified organisms, the role of precaution has coincided with widespread public disquiet throughout Europe (but not so much in North or South America and Asia) over the introduction of non-natural genes into living organisms, especially food crops. Here the application of precaution coincided with, and hence helped to buttress and articulately expressed pre-existing opposition by consumers. In the UK a three- year public listening process over the viability and safeguards over GM crops and foods resulted in persistent and continued outrage (Horlick-Jones et al 2007; see also Steinbrecher and Paul in this issue). Such opposition is pragmatically accepted by many major European food producers and retailers, so there is no effective commercial lobby in favor of GMOs except by the plant scientists and agricultural intensifiers. We see in this example of how it is possible for precaution still to have a role. But such a role probably has to be subsumed into a wider and more potent political anger supported in turn by the faltering emergence of 'caring capitalism'. Acting on its own, precaution is nowadays a weakened scientific and political weapon. But working supportively in resonant political or

\footnotetext{
${ }^{10}$ We return to this point below, in exploring the typically determinative importance of massive, previouslyunseen/unknown events: such as sudden 'jumps' or feedbacks in the climate system, when it passes novel thresholds.
} 
economic contexts, reference to the precautionary principle, especially when the timing for novel decisions is right, can tip the balance.

GMOs form one of the main examples both in the EU and elsewhere where the precautionary principle is being efficaciously employed to prevent something potentially dangerous which companies might otherwise have risked pursuing. This is taking place in response to a supposedly 'scientific consensus' that GMOs are safe. Even if such consensus was in existence, there is still a risk-asymmetry. A 99\% consensus that a plane is safe is not acceptable: the US Federal Aviation Authority standard is for an operational safety of more than $99.99 \%$. On the other hand, a mere $20 \%$ consensus that humantriggered climate change is real is already more than sufficient for us to worry deeply. An equivalent attitude to risk means that we should also take the dangers of GM technology very seriously indeed. The point is that, if we seek to weigh the proportionate consequences of the benefits of pursuing GMO crops or food, compared with the costs of not doing so, the 'balance' cannot be struck, if the downside is sufficiently bad. ${ }^{11} \mathrm{~A}$ sufficiently negative exposure in a 'tail-risk', even if the risk is adjudged as unlikely to be realized, outweighs any potential benefit ${ }^{12}$.

Establishing these thought-processes, putting them to the test, is precaution in action. A safety-first approach would not accept the meme that GM crops, having been tested for 20 years, are safe. For 20 years is no time at all on an ecological let-alone an evolutionary timescale. Without careful controlled and independent long-term study at organism and ecological scales (study which, at our current state of technology, it is hard to see how it could be safely undertaken at all), it is incorrect to claim the GMOs have in general been shown to be safe. And precaution requires us to put safety first.

New transgenic techniques (see Steinbrecher and Paul's article in this issue) are allegedly a more precise extension of other breeding techniques. But it would be a false opposition to paint opponents of GM as necessarily supporters of all 'conventional' breeding techniques, such as mutation by radiation. What the precautionary principle enjoins is the requirement to search for solutions that are not potentially ruinous. Such solutions as agroecology, seedsaving and permaculture do exist. To help arrive at the best decisions/solutions is where the deliberative roles of the proportionality test come in.

\footnotetext{
${ }^{11}$ See http://www.fooledbyrandomness.com/pp2.pdf . (Our deep thanks to Nassim Taleb for direct inspiration for with regard to this section of the present article.)

${ }^{12}$ We pick this point up in "New frontiers for precaution", below.
} 
In this series of four articles we note a number of common themes which bear on our discussion to this point. Anne Chapman looks at the role of evidence both from an ethical perspective and in relation to synthetic chemicals. She seeks to place both libertarianism and utilitarianism in the context of community based common harm. There are all manner of toxic substances and processes which may afflict the vulnerable or the next generation where evidence alone is not a sufficient moral or scientific guide. Chapman persuasively argues that higher standards of risk assessment should apply where individuals cannot escape the general harm and especially where vital but threatened ecological niches and processes are endangered. Here is where there should be higher standards of participation and more requirement of precautionary progress with clear liability on the generator of novel products.

lancu Daramus extends this line by showing that there are two corporate based arenas where liability and higher standards of precaution can and should be accommodated. One is the fiduciary duty placed on trustees and directors regarding the safeguards of wellbeing over generations. Here, he argues, higher standards of evidentiary proof should be required. Like Chapman and Steinbrecher and Paul, he makes a strong case for a more participatory sustainability science. Daramus also assesses the changing role of the financial and prudential regulators over corporate governance. It is becoming possible for the courts to demand that corporations take into account long term and uncertain climate change outcomes in the design and financial justification of their business strategies. In essence there is an emerging world of 'stress testing' for climate impact sensitivity.

Andrew Boswell takes these arguments into the international climate governance regimes. He seeks a more precautionary based approach to emerging climate regimes based on human rights, principles of fairness, and disaster prevention. He examines international law to show that rights based and justice linked approaches to handling precaution are now on the cards. But Boswell would like to go further. He seeks an extension of the body of law to encase the latest science of anthropogenic climate change and adaptation as the basis for future legally binding agreements. Ideally he would even change the fundamental basis of international law towards the strongest precautionary action on the basis that any further delay in emissions reduction would now likely be catastrophic (see the UN World Meteorological Association Status Report on the Global Climate 2016, 2017). We examine this particular issue below. Suffice it to say here that such calls, supported by climate science, are the very kind of reason why the precautionary principle is being so critically scrutinized.

\section{Updating the precautionary principle}


It is in the 'pro-growth' atmosphere of contemporary politics that the precautionary principle has been aggressively targeted by those who seem determined to prevent anything preventing the free rein of the 'free market' (American Enterprise Institute, 2016). There is an intriguing alliance of science and free-enterprise ideology in the contemporary attack on precaution. Free-enterprise advocates argue that, unless there is strong evidence of harm, then precaution is merely a pointless bar on innovation and profit-making. Paul and Steinbrecher point to the growing enthusiasm for the 'innovation principle' by the powerful pharmaceutical companies. Here the call is for the benefits of innovation to be weighed against known harm. This is a fundamental undermining of the original concepts of the precautionary principle. There is now a stand-off between this position and that of advocates of precaution who do not find sufficient support from scientists who are, as outlined above, extremely hesitant about potentially being responsible for false alarms, and who tend to rely upon a narrower evidence-based methodology.

When viewed in the proper context of philosophy/methodology of science and statistics, this so-called evidence-based stance is found wanting. Crucially, much of what is called evidence by those who want to downgrade the precautionary principle in the name of science and in support of free enterprise, is not statistically significant, especially, in relation to the potential for more or less catastrophic events (Taleb 2007; see also Taleb, Read et al 2014). Such events are by definition rare, so usually barely-evidenced. Where substantial evidence in the true sense of the word is lacking, the precautionary principle ought to fill the breach. ${ }^{13}$ In practice, it will only do so by a deliberate act of political or legal will for the most part spurred on by the public interest lobbies.

Serious irreversible harms are often determinative. This means that they far outweigh variations in the more normal run of events. Viewed in a suitably long term perspective, the kinds of vast potential harms that precaution is invoked to prevent, when they occur, matter far more than smaller harms and indeed than the kinds of small or even large benefits that scientists/technologists and free-marketeers may be keen to create. Irreversible events play a key, hard-to-overstate role in determining the course of human history.

\section{Brexit and the precautionary principle}

${ }^{13}$ Anne Chapman provides a robust moral and scientific support for this position. 
A particular threat to the precautionary principle in the UK, is connected to the UK leaving the EU in the next few years. ${ }^{14}$ The precautionary principle is present in UK law primarily through its being present in EU law. Prompted by one of us (Read), Caroline Lucas MP recently inquired in the UK Parliament about the status of the precautionary principle in the 'Brexit' process. The response from the government minister was that:

Article 191 of the Treaty on the Functioning of the European Union requires that EU legislation on the environment be based on the precautionary principle. The Prime Minister has announced a Repeal Bill to convert EU law into domestic British law, to provide certainty for consumers, workers and businesses by maintaining existing laws.

For the time being the precautionary principle is unchanged in UK law. It will be 'imported' into UK law along with everything else in EU law, as part of the Great Repeal process. Nevertheless, it will then be potentially vulnerable to removal or amendment by a simple UK parliamentary majority without full scrutiny. Much will depend on the legal and political procedures still to emerge. Unless the precautionary principle is specifically incorporated into a preamble of any new UK law, or appears as part of formal UK policy in the form of being incorporated into a White Paper (a legal guide to policy setting) then its current role will end (Haigh 2015). That could open the door to much weakened forms of regulation over the topics covered in our accompanying articles such as synthetic biology, GMOs, geoengineering experimentation, and emissions pathways. This appears to have been one of the motives for the Brexiteers wanting to leave the EU. ${ }^{15}$

\section{New frontiers for precaution}

In fields such as endocrine-disruption and radiation, it is now clear that "the dose does not always make the poison". Lower doses can be more harmful than higher doses. ${ }^{16}$ This sounds paradoxical. In order to see that it is possible, consider as an exemplar what a high dose of radiation may do to a cell: kill it. That is harmful, but potentially less harmful than what a lower dose may do to a cell: turn it cancerous.

It is increasingly unclear whether there is any safest low dose of some forms of some toxic substances. This challenges the so-called 'de minimis' principle of risk-regulation, very influential in the U.S., which seeks to impose minimum percentage-levels (e.g. one part in a

\footnotetext{
${ }^{14}$ Here is a recent example of the threat: http://www.cityam.com/253506/shelve-eus-anti-innovationprecautionary-principle.

${ }^{15} \mathrm{http} / / /$ www.endsreport.com/article/54076/paterson-calls-for-shift-away-from-precautionary-principle . (See also http://www.endsreport.com/article/55026/leadsom-to-roll-back-eu-environmental-farm-rules )

${ }^{16} \mathrm{Here}$ is a useful example, from the literature: see the first couple of paragraphs: https://www.ncbi.nIm.nih.gov/pmc/articles/PMC4429934/
} 
million) below which substances can be assumed to involve no risk. The prima facie question-mark against the old notion that 'the dose makes the poison' yields a revolutionary new argument favoring the strengthening and wider deployment of the precautionary principle. Until we are presented with strong empirical grounds for believing otherwise, we need to consider (and act on) the possibility in any new field or novel technology that lower doses might be more harmful than higher doses. Absence of evidence of harm at high doses not only does not imply evidence of absence of any harm. It also no longer implies absence of harm even at lower doses.

There has been some recognition of this kind of point. ${ }^{17}$ But so far as we can tell there has not been any serious philosophical/statistical/risk-analytical discussion of the phenomenon and its implications.

Our suggestion here is that an extended argument for precaution can be applied to any new arena of contentious toxicity as examined by Anne Chapman. Until one has reliable epidemiological good reason to believe that a low dose actually is safe, one should precautiously assume that it is not. Thus, in contrast to what is widely assumed, there is good reason here to believe that there may be no safe dose of any novel product or process which is not yet fully tested. ${ }^{18}$ This leaves open the theme of how does one safely or ethically conduct such tests. ${ }^{19}$

The fields of philosophy and sustainability science need to deepen their understanding of these matters. Sustainability science needs to move beyond the lingering fixation upon evidence alone, and upon relatively short time-scales that has left even this approach to science at times comparatively open to unwanted alliances with those who want to restrict further the precautionary principle. Sustainability science in alliance with ethics, philosophy, statistics, and with activism, can reshape the image and governance role of those areas of science that matter most, publicly and consequentially, for the age of 'Anthropocene'.

\footnotetext{
17 See e.g. this impressive European Parliament resolution: http://www.europarl.europa.eu/sides/getDoc.do?pubRef=//EP//TEXT+REPORT+A7-2013-0027+0+DOC+XML+V0//EN.

${ }^{18}$ The word "novel" here is crucial. There are plenty of things that we know are safe because we have used them since time immemorial, and indeed have co-evolved with them. The precautionary principle's 'natural home' is in relation to novelty that threatens disaster, the form of genuine novelty found in (for instance) the synthesization of new chemicals, not the less-threatening novelty involved in simply innovating within the context of what is familiar, natural, or known as safe.

${ }^{19}$ The point here is similar to that that implied above concerning what a really safe testing regime would be for GM crops/food. The point is this: if one lacks a technology that would enable really safe testing, then precaution enjoins that one should wait, and not test, let alone roll out the technology, until one has the ability to conduct such testing safely. Otherwise, the 'testing' is itself reckless.
} 
Reformulating sustainability science into a more ethics-based framework would help to put precaution back in its rightful place. A place where it might yet help prevent the economic forces intent on stripping out our common protections from succeeding. Those forces are gaining ground just as we so clearly - indeed, desperately - need safeguards against our species' own excesses and unknown future harms. We commend this issue of Environment to you, and hope that you will join us in thinking through - and acting on - the reasons why the Precautionary Principle can manifest exactly such a safeguard.

\section{Box 1. Ethical considerations}

We should recognize as did Socrates that often the wisest path is to admit that we are more ignorant than we like to believe. We should accept that we live in a world that in many ways we do not fully understand. We should learn to live in a world of varying levels of ignorance and uncertainty, rather than harboring hubristic, dangerous ambitions for 'total' explanation and mastery. It is precisely for living in such a world that the precautionary principle is designed.

We should acknowledge when there are or might be insufficiencies with our models and evidence, as presented in the accompanying papers. When we then create plans of action we should also consult those familiar with philosophy and statistics.

Where the stakes are high, we should err decisively on the side of caution. We should reject claims of high degrees of safety when the evidence on which those claims are based is not solidly statistically grounded. We must recognize when such evidence does not encompass drastic possible outliers which could distort the whole graph, particularly when the long view should be awarded full credence.

\section{References}

Boehmer-Christiansen, S. "The Precautionary Principle in Germany - Enabling Government”, in T. O'Riordan and J. Cameron, eds. Interpreting the Precautionary Principle (London, Cameron May 1994) 31-60.

Jordan, A. "The Precautionary Principle in the European Union”, in T. O'Riordan, J. Cameron and A. Jordan eds. Reinterpreting the Precautionary Principle London, (Cameron May, 2001), 143-161.

Gee, D. ed. Late Lessons from Early Warnings: Science, Precaution, Innovation, (Copenhagen, European Environment Agency, 2013). 
Owens, S. Knowledge Policy and Expertise: The UK Royal Commission on Environmental Pollution, 1970-2011, (Oxford, Oxford University Press, 2015).

Royal Commission on Environmental Pollution, Lead in the Environment, (London, Stationary Office, 1983).

Taleb, N.N. The Black Swan. (Penguin, 2007).

Taleb, Read et al. "The precautionary principle (with reference to the genetic modification of organisms)" (http://www.fooledbyrandomness.com/pp2.pdf 2014).

Wilson, D. The Lead Scandal (Heinemann, 1983).

Environment Audit Committee, National Pollinator Strategy, (London, Stationary Office, 2016).

American Enterprise Institute, http://www.polluterwatch.com/ (Washington, American Enterprise Institute via Greenpeace).

UN World Meteorological Association Status Report on the Global Climate, (New York, World Meteorological Organization, 2016, 2017).

Horlick-Jones, T., Walls, J., Rowe, G., Pidgeon, T. Poortinga, W., Murdock, G. and O'Riordan, T. The GM Debate: Risks, Politics and Public Engagement. (London, Routledge, 2007).

Stockstad, E, et al. European bee study fuels debate over pesticide ban. Science (2017), 356 (6345), 1321.

Woodcock, W.A. et al. Country specific effects of neonicotinoids on honey bees and wild bees. Science (2017), 356, 6345, 1393-1395.

Haigh, N. EU Environmental Policy: Its Journey to Centre Stage. (Earthscan, London 2015) 